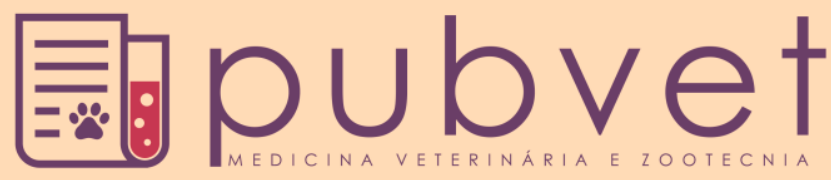

10.31533/pubvet.v12n10a189.1-5

\title{
Deslocamento de abomaso à esquerda efêmero em uma vaca lactante da raça Jersey: Relato de caso
}

\author{
Jéssica Serafim ${ }^{1 *}{ }^{\bullet}$, Cássio da Rosa ${ }^{2}$, Aline Bruschi Bielski ${ }^{3}{ }^{\bullet}$, Gilson Antônio Pessoa ${ }^{4} \bullet$, \\ Mateus Cestonaro ${ }^{5}$ C
}

${ }^{1}$ Graduando em Medicina Veterinária, Universidade de Caxias do Sul. Caxias do Sul-RS, Brasil. ${ }^{2}$ Graduando em Medicina Veterinária, Universidade de Caxias do Sul. Caxias do Sul-RS, Brasil.

${ }^{3}$ Médica veterinária formada pela Universidade de Caxias do Sul. Bento Gonçalves-RS, Brasil.

${ }^{4}$ Dr., Prof., Universidade Federal de Santa Maria, Departamento de clínica de grandes animais. Santa Maria - RS, Brasil.E-mail: gilsonpessoavet@hotmail.com ${ }_{5}^{5}$ Médico veterinário formado pela Universidade de Passo Fundo. Nova Bassano-RS, Brasil.

*Autor para correspondência: jessicasera-17@hotmail.com

RESUMO. O deslocamento de abomaso é uma patologia comum em vacas de alta produção leiteira. Devido aos poucos relatos na literatura de deslocamento transitório de abomaso, este relato descreve a ocorrência de deslocamento de abomaso à esquerda com curso recorrente em uma vaca Jersey lactante. O animal foi monitorado durante três dias, onde observou-se que em determinadas horas do dia ocorria o deslocamento do órgão. Diante do caso, foi optado pelo procedimento cirúrgico de abomasopexia pelo flanco esquerdo, já que é o tratamento de eleição. Após a abordagem cirúrgica, o animal voltou a se alimentar normalmente. Quanto antes for realizado o diagnóstico, melhor será o prognóstico do paciente.

Palavras chave: abomasopexia, deslocamento de abomaso efêmero, Jersey, vaca leiteira

\section{Transitory left displaced abomasum in a milking Jersey cow: Case report}

ABSTRACT. Displaced abomasum is a common pathology in high milk production cows. Due to few literature reports in transient displaced abomasum, this report describes the surgery correction of the left displaced abomasum with recurrent course in a lactating Jersey cow. The animal was monitored for three days, where it was observed that at certain moments of the day the organ displacement occurred. In view of the case, the abomasopexy procedure by the left flank was chosen, since it is the treatment of choice. After the surgical approach, the animal returned to normal feeding. The sooner the diagnosis is made, the better the patient's prognosis.

Keywords: abomasopexy, transitory displaced abomasum, Jersey, dairy cattle

\section{Desplazamiento de abomaso a la izquierda efímero en una vaca lechera de la raza Jersey: Reporte de un caso}

RESUMEN. El abomaso desplazado es una patología común en vacas de alta producción lechera. Este relato describe la incidencia del desplazamiento transitorio de abomaso a la izquierda recurrente en una vaca Jersey lactante. El animal fue monitoreado durante tres días, donde se observó que en ciertos momentos del día ocurría el desplazamiento del órgano. En vista del caso, se opto por el procedimiento quirúrgico de abomasopexia por el flanco izquierdo, ya que es el tratamiento de elección. Después del abordaje quirúrgico, el 
animal volvió a alimentarse normalmente. Cuanto antes se realice el diagnóstico, mejor será el pronóstico del paciente.

Palabras clave: abomasopexia, abomaso desplazado transitorio, Jersey, vacas lecheras

\section{Introdução}

O deslocamento de abomaso é um problema comum em vacas de alta produção leiteira, logo após o parto e até algumas semanas depois (van Winden, 2002; Santarosa, 2010; Marques et al., 2016). Podendo ocorrer o deslocamento do abomaso para o lado esquerdo (DAE) ou para o lado direito (DAD) e ou ainda, torção do abomaso (TA); porém, de 85 a $96 \%$ da ocorrência são DAE (Câmara et al., 2010; Santarosa, 2010; Motta et al., 2015).

A etiologia é multifatorial, portanto, fatores como acidose ruminal subclínica, laminite, hipocalcemia, mastite, retenção de placenta, metrite e cetose podem ser fatores predisponentes para a ocorrência de deslocamento de abomaso (Câmara et al., 2010; Motta et al., 2015; Marques et al., 2016). Estas enfermidades levam a diminuição do consumo alimentar, ocasionando à atonia/hipotonia do trato digestivo e posterior acúmulo de gás no abomaso, o que pode levar ao deslocamento deste (Patelli et al., 2013; Patelli, 2014).

O impacto econômico é relevante. O deslocamento de abomaso causa perdas devido o descarte do leite, custo de tratamento e cirurgia, perda de peso do animal, diminuição da produção, maior intervalo entre partos, descarte prematuro do animal e, até, mortalidade (Cardoso, 2008; Santarosa, 2010; Patelli et al., 2013). Para diminuir a incidência da enfermidade, deve-se fornecer uma dieta balanceada e rica em fibra, além da utilização de drench logo após o parto e nos próximos cinco dias (Kass et al., 2013). O prognóstico é favorável na maioria das vezes (Câmara et al., 2010; Santarosa, 2010). Para a correção desta enfermidade pode ser utilizado procedimentos, como a abomasopexia pelo flanco direito ou esquerdo, a omentopexia pelo flanco direito ou esquerdo e a abomasopexiaparamedianaventral (Hendrickson, 2010). Além disso, há o método de rolamento com suturas às cegas, técnica de "toggle-pin" (ainda utilizada nos EUA). Técnicas essas com o auxílio do laparoscópico e piloropexia (Câmara et al., 2011).

O objetivo deste estudo é relatar o diagnóstico e a conduta terapêutica realizada em um caso de deslocamento do abomaso transitório à esquerda em uma vaca da raça Jersey pós-parto.

\section{Relato do caso}

Em abril de 2017, no município de Nova Bassano - RS foi atendida uma vaca da raça Jersey, de aproximadamente $400 \mathrm{~kg}$, aos 10 dias em lactação e puerpério precoce, multípara (terceiro parto) e escore de condição corporal 2,5 (em escala de 1 a 5). Durante a anamnese o proprietário informou que o animal havia diminuído a ingestão de alimentos, apresentando perda rápida da condição corporal, além da queda na produção de leite. Ao exame clínico apresentou som de ping metálico no abdômen do lado esquerdo, rúmen sem motilidade e desidratação de $10 \%$. A temperatura corporal, frequências cardíaca e respiratória estavam dentro dos parâmetros fisiológicos para a espécie. O diagnóstico foi realizado de acordo com os sinais clínicos, concluindo ser um deslocamento do abomaso para o lado esquerdo.

O tratamento estabelecido foi o cirúrgico, que seria realizado algumas horas após o diagnóstico. Ao momento de iniciar o procedimento cirúrgico foi realizado um exame clínico e notou-se que não havia mais o som de ping metálico e o animal estava ingerindo um pouco de alimento, vagarosamente. A partir disso, o animal foi monitorado durante três dias. Observou-se que a partir das $08 \mathrm{~h} 30$ da manhã até aproximadamente $11 \mathrm{~h} 00$, o abomaso ficava na sua posição anatômica. Porém, a partir das $11 \mathrm{~h} 00$ até $14 \mathrm{~h} 30 \mathrm{o}$ abomaso encontrava-se deslocado para o lado esquerdo. Após as $14 \mathrm{~h} 30$ até por volta de $19 \mathrm{~h} 00$, o órgão voltava à sua posição anatômica. Já, a partir das $19 \mathrm{~h} 00$ até aproximadamente as 08h30 do próximo dia, o abomaso se encontrava deslocado. No terceiro dia de monitoramento, às 13 h00 foi realizado o exame clínico, concluindo que novamente havia o deslocamento do abomaso para o lado esquerdo, onde se realizou $o$ procedimento cirúrgico de abomasopexia pelo flanco esquerdo com sutura não absorvível. $\mathrm{O}$ animal permaneceu em estação durante $o$ procedimento.

Realizou-se a lavagem com água e detergente líquido da área onde o procedimento cirúrgico seria executado, após fez-se a tricotomia e novamente lavagem do local com água $\mathrm{e}$ detergente líquido, sendo a secagem do local feita com papel toalha. Após isso, foi realizada a 
antissepsia do local com álcool (70\%), iodo e álcool (70\%). A tranquilização foi realizada com acepromazina (Acepran 1\% ${ }^{\circledR}$, Vetnil, Brasil) na dosagem de $0,5 \mathrm{ml} / 100 \mathrm{~kg}$, administrado via intramuscular. A anestesia local foi realizada por bloqueio linear na linha da incisão com cloridrato de lidocaína (Lidovet ${ }^{\circledR}$, Bravet), utilizando o total de $80 \mathrm{~mL}$. Durante o procedimento cirúrgico, foi administrado fluidoterapia (Suprevit ${ }^{\circledR}$, Labovet) na dose de $500 \mathrm{ml}$ via intravenosa, utilizado como veículo para a dipirona sódica (D-500 ${ }^{\circledR}$, Zoetis Fort Dodge), na dose de $20 \mathrm{~mL}$.

A incisão cirúrgica foi realizada na fossa paralombar esquerda. Após acessar a cavidade abdominal, o abomaso foi visualizado. Para a fixação foram realizados seis pontos simples contínuos na curvatura maior do abomaso utilizando fio de nylon 1, mantendo o fio livre (aproximadamente $20 \mathrm{~cm}$ ) nas duas extremidades da sutura (Figura 1). Imediatamente, o órgão foi canulado com um equipo de inox com ponta em bisel e uma mangueira foi acoplada ao equipo, para que saísse todo o ar para facilitar a colocação do órgão na posição anatômica (Figura 2).

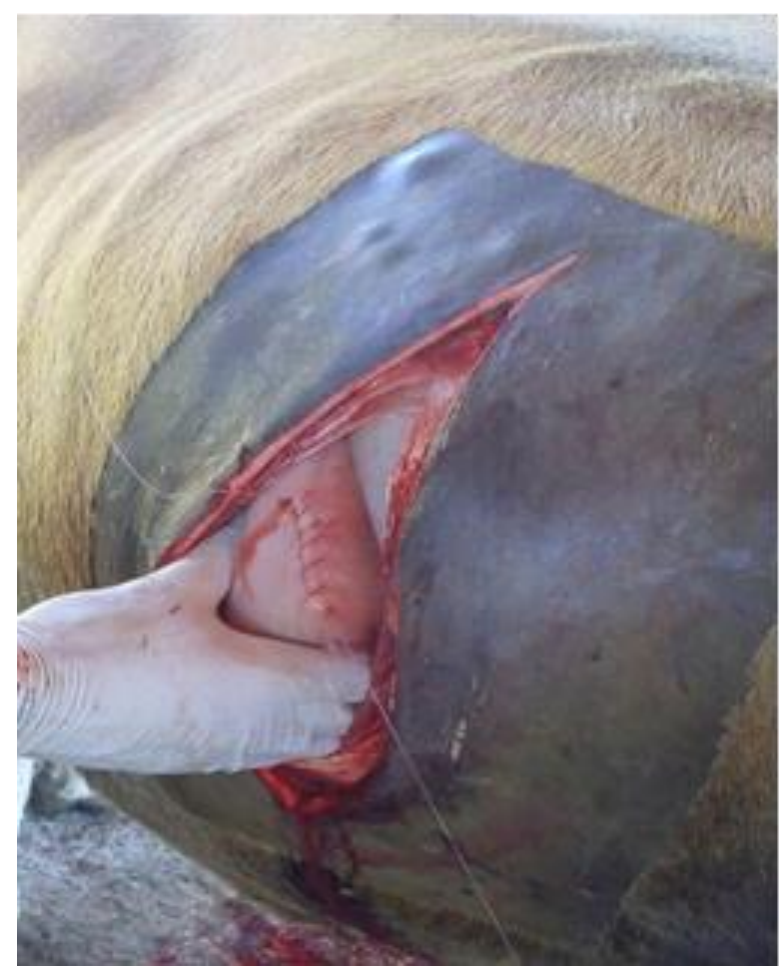

Figura 1. Imagem demonstrando a sutura simples contínua na curvatura maior do abomaso e as extremidades livres do fio de nylon.

Com o auxílio de uma agulha de sutura em $\mathrm{S}$ para bovinos foi passada a ponta do fio de nylon próximo ao processo xifóide do esterno, onde o auxiliar tracionou as duas pontas do nylon, enquanto o cirurgião colocou o órgão em seu local anatômico. Foi realizado um ponto isolado simples unindo as duas pontas do fio. Para que não houvesse aderência do abomaso à cavidade abdominal, uma distância correspondente à dois dedos foi mantida entre o órgão e o assoalho da cavidade abdominal.

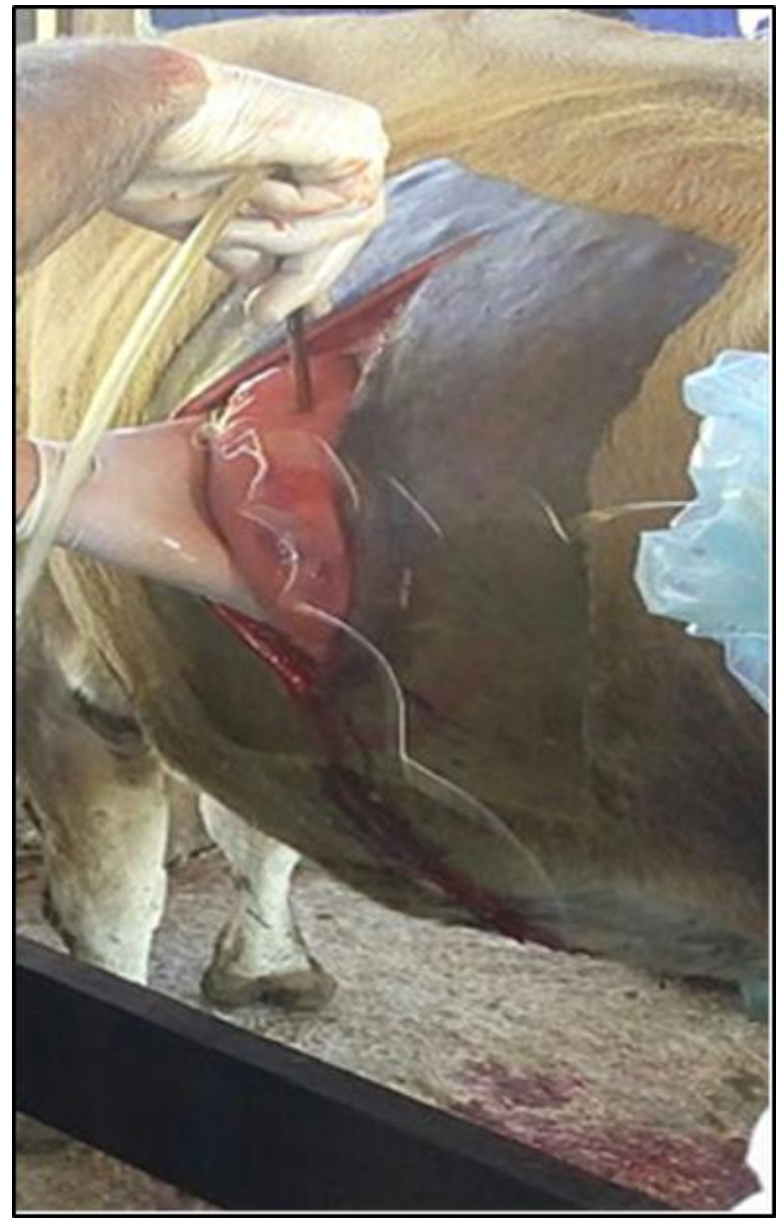

Figura 2. Perfuração do abomaso para a retirada do gás

Após isso, realizou-se a síntese do peritônio e a camada muscular, com sutura simples contínua e a pele com padrão de sutura ancorada de Ford; todas com fio de nylon. No pós-operatório foi administrado $40 \mathrm{~mL}$ via IM de Dipirona Sódica (D-500 ${ }^{\circledR}$, Zoetis - Fort Dodge, Brasil), $10 \mathrm{~mL}$ via IM de Flunixina Meglumina (Banamine ${ }^{\circledR}$ ), $40 \mathrm{~mL}$ via IM de Benzilpenicilina/ Dihidroestreptomicina (Shotapen ${ }^{\circledR}$, Virbac, Brasil) e repelente no local (Bactrovet Prata A.M - Sulfadiazina Prata - 500 $\mathrm{ml}^{\circledR}$ - König-Brasil). Todos esses medicamentos foram utilizados durante três dias.

Após duas horas do término do procedimento o animal voltou a ingerir a dieta normalmente. A retirada dos pontos da pele foi realizada após 10 dias, e o ponto de fixação feito próximo ao esterno foi retirado após 40 dias. A correção da dieta foi 
realizada adicionando-se volumoso com maior quantidade de fibra.

\section{Discussão}

Os sinais clínicos comuns do deslocamento de abomaso, de acordo com Câmara et al. (2010) e Santarosa (2010) são anorexia, queda na produção leiteira, desidratação, movimentos ruminais diminuídos ou ausentes, fezes escuras, fétidas, secas e escassas, temperatura retal, frequência cardíaca e frequência respiratória normal ou levemente aumentados, polidipsia e fraqueza muscular. Porém, não foi observado polidipsia e fraqueza muscular no animal relatado. Dentre esses sinais clínicos, Cardoso (2008) afirma que o animal pode parar de ingerir alimentos concentrados; porém continua a ingestão de forragens. Neste caso, o animal apenas ingeria alimento quando o abomaso voltava à posição anatômica.

O procedimento cirúrgico realizado foi a abomasopexia, que é descrita como tratamento cirúrgico de eleição por Marques et al. (2016). De acordo com Hendrickson (2010) os pontos cirúrgicos realizados próximos ao processo xifóide, tem indicação de retirada após 4 semanas do procedimento; porém no relato permaneceram por 40 dias. Além dos medicamentos utilizados no pós-operatório, há indicação de que seja fornecido cloreto de sódio e de potássio, para adequar o equilíbrio hidroeletrolítico e estimulantes de motilidade, como a neostigmina (Hendrickson, 2010). Ainda, Hendrickson (2010) indica a neostigmina apenas se o animal não apresentar motilidade de 24-48 horas pós-cirúrgico.

Deve-se ter o cuidado para que o abomaso não fique muito pressionado contra o assoalho do abdômen, pois pode gerar uma aderência do órgão, resultando no desenvolvimento de úlceras gástricas de grau III e IV (Câmara et al., 2011). Devido a isso, um espaço correspondente a dois dedos de distância entre o assoalho e o órgão foi mantido. A desvantagem da realização deste procedimento é o risco de perfuração de vísceras enquanto a agulha é levada até o assoalho do abdômen. Além disso, a utilização de fios nãoabsorvíveis que passam no lúmen do abomaso pode potencializar a proliferação bacteriana resultado da fistulação (Hendrickson, 2010). Deve-se ter, também, cuidado ao fazer a fixação do órgão, para que não ocorra a perfuração da veia mamária (Câmara et al., 2011).
Como medida preventiva para o deslocamento de abomaso pode-se fazer uso de drench. Este possui propilenoglicol, propionato de cálcio ou de sódio e glicerol diluído em 30 a 40 litros de água morna (Kass et al., 2013). É fornecido ao animal através de uma sonda esofágica e tem como finalidade evitar cetose, hipocalcemia e deslocamento de abomaso, além de hidratar o animal. Além disso, na dieta pré-parto, o fornecimento de bastante fibra, pouco concentrado e a utilização de cápsula de monensina três semanas antes do parto, para que aumente a formação de propionato, pode ser uma opção. Com a utilização de monensina ocorre redução em $40 \%$ dos casos de deslocamento de abomaso, e $25 \%$ dos casos de retenção placentária (Gordo, 2009). A prevenção de outras doenças que acometem vacas no pós-parto auxilia na prevenção do DA, já que este normalmente é decorrente de outras enfermidades (Santarosa, 2010).

\section{Conclusão}

O diagnóstico precoce é de extrema importância para estabelecimento do tratamento e efetividade do mesmo, tendo influência direta ao prognóstico clínico do paciente. $\mathrm{O}$ tratamento cirúrgico é de eleição para o deslocamento de abomaso. A abomasopexia pelo flanco esquerdo se mostrou eficiente para correção da patologia, havendo melhora clínica e produtiva do animal. Existem poucos relatos sobre deslocamento de abomaso transitório, sendo necessários mais estudos sobre o assunto.

\section{Referências}

Câmara, A. C. L., Afonso, J. A. B., Borges, J. R. J., 2011. Métodos de tratamento do deslocamento de abomaso em bovinos. Acta Veterinaria Brasilica 5, 119-128.

Câmara, A. C. L., Afonso, J. A. B., Costa, N.d.A., Mendonça, C.L.d., Souza, M.I., Borges, J.R.J., 2010. Fatores de risco, achados clínicos, laboratoriais e avaliação terapêutica em 36 bovinos com deslocamento de abomaso. Pesquisa Veterinária Brasileira 30, 453-464.

Cardoso, F., 2008. Indicadores hematológicos, bioquímicos e ruminais no diagnóstico do deslocamento de abomaso à esquerda em vacas leiteiras do Sul do Brasil. Pesquisa Agropecuária Brasileira 43, 141-147.

Gordo, R. I. N., 2009. Contribuição para o estudo do deslocamento do abomaso numa 
exploração leiteira da região de Montemor-oVelho, Faculdade de Medicina Veterinária, Universidade Técnica de Lisboa, Lisboa.

Hendrickson, D. A., 2010. Técnicas cirúrgicas em grandes animais, Guanabara Koogan, Rio de Janeiro, Brasil, p. 238 p.

Kass, M., Ariko, T., Samarütel, J., Ling, K., Jaakson, H., Kaart, T., Arney, D., Kärt, O., Ots, M., 2013. Long-term oral drenching of crude glycerol to primiparous dairy cows in early lactation. Animal Feed Science and Technology 184, 58-66.

Marques, T. O., Sá, M. A. F., Pereira, N. B. A., Galvão, A., Rocha, F.S., 2016. Deslocamento de abomaso à esquerda em bovinos de leite no sul de Minas Gerais - Relato de quatro casos. . Revista Científica de Medicina Veterinária 27, 1-10.

Motta, R.G., Motta, I. G., Botelho, A. C. F. A., Gheller, J. M., Souza, A. M., Baldin, T., Momo, R., Schreiber, J., Barbosa, L. C., Ribeiro, M. G., 2015. Deslocamento de abomaso à esquerda em bovino-relato de caso. Atas de Saúde Ambiental-ASA 2, 53-61.

Patelli, E. M., 2014. Deslocamento do abomaso à esquerda em bovinos leiteiros: da etiologia ao diagnóstico. Faculdade de Medicina e
Veterinária, Universidade Estadual de São Paulo, Araçatuba.

Patelli, T. H., Souza, F. A., Rosa, F. V., Barreiros, T. R., Marques, L. C., 2013. Impactos econômicos do deslocamento de abomaso em uma propriedade leiteira no município de Carambeí, estado do Paraná. Ars Veterinária 29, 8-12.

Santarosa, B. P., 2010. Deslocamento de abomaso em vacas leiteiras, Faculdade de Medicina Veterinária e Zootecnia, Universidade do Estado de São Paulo, Botucatu.

van Winden, S. C. L., 2002. Displacement of the abomasum in dairy cows: risk factors and preclinical alterations, Curso de Medicina Veterinária, Utrecht University, Utrecht.

Recebido: 1 Agosto, 2018.

Aprovado: 20 Agosto, 2018

Publicado: 28 Setembro, 2018

Licenciamento: Este artigo é publicado na modalidade Acesso Aberto sob a licença Creative Commons Atribuição 4.0 (CC-BY 4.0), a qual permite uso irrestrito, distribuição, reprodução em qualquer meio, desde que o autor e a fonte sejam devidamente creditados. 